\title{
Paradoxical lived experiences of the newly-hired faculty in a university setting
}

\author{
Ivy T. Eran ${ }^{1 *}$, Manuel E. Caingcoy ${ }^{2}$ \\ 1, 2 Bukidnon State University, Malaybalay City, Bukidnon, Philippines
}

\author{
Keywords \\ Educational administration \\ Experiences \\ Instruction \\ Research \\ Extension \\ Production \\ Received: 9 August 2019 \\ Accepted: 6 September 2019 \\ Published: 31 October 2019
}

\begin{abstract}
This study explored the experiences of the newly-hired faculty in the university to acquire an in-depth and profound understanding of these experiences. It involved eight purposively chosen faculty in a semi-structured interview and focus group discussion documented in voice and video recorders. Using Colaizzi's seven step-approach to data analysis, results revealed three paradoxical themes: the joys and struggles of teaching, successes and pains of learning, and the privileges and challenges of serving. On the one hand, the joys and struggles of teaching were brought about by their adjustments in instruction. On the other hand, successes and pains of learning centered on professional growth. Finally, the privileges and challenges of serving incorporated the experiences in research, production, and extension. Generally, these teachers have experienced ups and downs in their first two years of teaching at a higher education institution. On the basis of study findings, implications and recommendations are discussed.
\end{abstract}

(C) 2019 The Author(s). Published by TAF Publishing

\section{INTRODUCTION}

Faculty who are new to the organization may experience a period of adjustment. This period may bring them to either positive or negative experiences. The adjustment and experiences highly depend on the system they come from, and it may count more if they come from a system with a different setup, processes and procedures. Some of them could easily adjust to the new environment, while it would take others a long time to fully integrate themselves into the organization.

Being employed in a university could somehow make newly-hired faculty feel motivated and excited. This is for the reason that they qualified for their eligibility and competence over other applicants who were also competent to do the job. However, this motivation and excitement need to be sustained over time. Due to high expectations, the newlyhired faculty experience problems and challenges that may come along as they practice their profession. At the beginning of the school year, it is hard for them to untangle all the tasks such as dealing with paper works, new learners, varying class activities, and others (Joonlaoun, 2017; Lancu, 2013). On the other hand, some of them could easily adjust as they were used to deal with the same work in their previous employment. Experiences of newly-hired faculty in instruction may include lesson preparation. Lessons should be carefully planned and organized as they cater to the needs of diverse learners. The faculty need to be innovative and creative to make the teaching-learning process enjoyable and meaningful. With the workload, the faculty may attend not only to lesson preparation, but also to other responsibilities they are expected to fulfill.

With the nature of the learners, teachers may encounter behavioral problems, and these may be accompanied by parents' monitoring on the performance of their children. The new faculty may encounter difficulty in dealing with learners and parents. Despite the struggles encountered by the newly-hired faculty and with the intent of becoming effective educators, they need to cope with the challenges. They

${ }^{*}$ corresponding author: Ivy T. Eran

†email: ivytaneran@gmail.com 
need to exert effort and render time to execute their functions effectively. Faciolan and Guhao (2016) affirmed that it is normal for newly-hired teachers to experience satisfaction and dissatisfaction; pleasure and pain; and joy and sadness.

Promoting professional growth and development among newly-hired faculty is necessary. Attending seminarworkshops, addressing challenges and problems, and seeking support from colleagues are ways to grow professionally. To make lesson planning and preparation easier, the guidance of other teachers is necessary so that they can plan and use the curriculum to its utmost potential (Dias-Lacy \& Guirguis, 2017; Gam, 2018; Pwint, 2016). Therefore, mentoring them is necessary for professional growth and development. Moreover, they are also expected to foster a smooth relationship with colleagues.

The newly-hired faculty play not only the role of a teacher but also as researchers and "extensionists", among many other functions. Faculty members are encouraged to present research papers as part of the pillars of the organization. This endeavor may contribute to the development of the university as well as to the faculty's promotion. They are also encouraged to render extension services, which may entail additional lesson preparation, instructional material, or any activity that may entirely be different from the usual tasks of a teacher, depending on the nature of the extension service rendered. Moreover, teachers are also encouraged to be innovative by producing instructional materials. The administration persuades them to create instructional materials that can aid effective teaching and learning. Despite the bulk of work that all these functions cover, the endpoint is that all these undertakings benefit both the university and the newly-hired faculty.

The study conducted by Didatoon (2016) focused on the instructional competences of the newly-hired teachers included activities inside the classroom. The study also discussed teachers' difficulty in finding teaching strategies and production of instructional materials, lesson planning, classroom management, and assessment. On the other hand, Peria (2015) conducted a study on the positive and negative emotions of newly-hired teachers based on their experiences as beginning teachers.

The aforementioned studies mostly covered the area of instruction while there was little focus on instructional materials development. Additionally, the studies encompassed the emotions of newly-hired teachers but did not explore the areas of research and community service. With these studies, experiences of newly hired faculty with broader coverage may not have been taken into consideration in the past.

\section{Objectives}

This study explored the lived experiences of the newly hired faculty in a chosen university in the Philippine setting. Upon giving a deep and thorough understanding of their lived experiences, these faculty and the administration could reflect on and find ways in handling problems, addressing challenges, and taking action to the concerns of the faculty that may negatively affect their general welfare including work performance. The results of this study would serve as a baseline for the different programs and activities that may benefit them. The institution may be guided and may incorporate the faculty's experiences for policy consideration. Finally, this research may encourage future researchers to conduct similar study in their schools.

\section{METHODOLOGY}

The study used a phenomenological approach to qualitative research to explore the different experiences encountered by the newly- hired faculty. In this type of research, the phenomenon takes place in the natural setting (Creswell \& Creswell, 2017). Its purpose was to entirely understand the real meaning of a phenomenon such as the experiences of the newly-hired faculty. This phenomenological research aimed also to describe and shed light on the experiences of participants to figure out the essence of these experiences as remarked by the participants. This study would reveal trends of their views and opinions as it delved into their experiences.

The study was conducted at the Bukidnon State University, College of Education. In January 2017, this university hired 55 new faculty in which 13 were assigned to the College of Education in which eight of them were recruited as participants. They were chosen based on their previous experiences. Specifically, they were all former teachers in the Department of Education who had experienced teaching at elementary and secondary levels. When hired in this university, they were assigned to the different curricular programs.

This study conducted interviews and focus group discussions with the participants who shared their experiences. During the FGD and interviews, the researchers took note of the facial expressions and gestures of the participants. This would aid in describing their feelings. The sincere atmosphere during the discussion was encouraged so that they can reveal their behaviors, beliefs, opinions, and experiences on every question.

This study observed the ethical guidelines in conducting re- 
search. The researchers respected the rights and dignity of the participants, thus, their welfare was protected. Before the study was conducted, a letter addressed to the President of the university was endorsed requesting permission to allow the researchers to conduct the study in the university. Upon approval, the researchers sent invitation letters to the participants. The letter contained information on the purpose of the study and the nature of their participation. An informed consent form was also given to the participants prior to the conduct of the interviews and focus group discussion. The consent to participate meant that they accepted the invitation to participate in the interview and FGD; they agreed to provide relevant information and answer the questions honestly. It also included an agreement for the researcher to document the proceedings through video recorder; and the participant could withdraw their participation for valid reasons. The transcripts were checked by them to confirm their answers. They were also assured of the privacy and confidentiality of the information they provided. Interviews were conducted on the preferred time of the participants. They were given ample time to answer the questions and allowed them to use any language they are comfortable with so that they could give their honest answers. The focus group discussion was conducted to validate the information gathered during the interview. Participants were gathered on the agreed date, time and venue. The researchers only served as documenters, overseers and facilitators.

The researchers familiarized the data by reading the participants' narratives several times. Morrow, Rodriguez, and King (2015):

(1) In identifying significant statements, they included all statements in the participants' answers that were straightforward and significant to the phenomenon under study; (2) They identified meanings pertinent to the phenomenon that resulted from a thorough deliberation of the important statements; (3) In clustering themes, they grouped the recognized meanings into themes that were most likely common among participants' experiences; (4) In developing an in-depth account, they transcribed a wide-ranging and comprehensive description of the phenomenon, integrating all the themes; (5) In producing the fundamental structure, they summarized the in-depth description down to a brief, dense statement that seizes just those parts that were vital to the structure of the phenomenon; (6) and lastly, to verify the fundamental structure, the researcher revisited all the participants to confirm whether it captured their experiences.

\section{RESULTS AND DISCUSSION}

After re-reading the transcripts several times, responses were then grouped into three themes, namely: the joys and struggles of teaching; successes and pains of learning; and the challenges and privileges of serving. The first theme refers to the lived experiences of the newly-hired teachers in instruction, while the second theme has something to do with their experiences in professional development. Lastly, the third theme covers their experiences in research, extension and development.

\section{Joys and Struggles of Teaching}

On one hand, the newly-hired faculty described their experiences in instruction. and they were not able to control themselves from comparing their experiences in BukSU with their previous employment. Some of them did it just to emphasize and stress that being employed at BukSU is better off than their previous employment at the the Department of Education. This constitutes their joys of teaching. On the other hand, they also shared the 'not so good' experiences in instruction. This would suggest that although it is gainful to work in the university, still there were difficulties they experienced. Thus, their experiences in instructions are both joyful and struggling ones.

The faculty took part in providing quality teaching and learning. By doing this, they could tell stories on their first two years of teaching. Bartell (2004) considered the first three years of teaching as initial years of service to familiarize themselves with the responsibilities in the new workplace. They may have experienced a sense of fulfillment while they fulfill their responsibilities with joy. Job satisfaction may be felt in the workplace if their needs were provided and attended. The first two years of being in the university were concentrated on their adjustment. This is a normal process when one faculty transfers from one job to another. Based on their responses, a few of them are still undergoing this phase, while for most of them they have already adjusted in the university's systems, culture and tradition. Thus, they have fully integrated themselves into the organization. As narrated:

The experiences for two years, I think I would say that it's great (P1).

This response clearly implies that the previous experience helped the faculty to easily adjust to the current environment and its system. Likewise, one has shared:

I'm from the basic education at the Department of Education. When I came here, there was no major adjustment since I am assigned to the Elementary department (P3). Consequently, some faculty experienced little adjustments 
as they were handling the same level of learners with their previous stations while another faculty had experienced as a guest lecturer in this university. Both experiences have become advantages. One of them considered that staying in university is less stressful and is convenient. This was the reason why one said:

I describe my two years as it's not that stressful (P3). Therefore, these newly-hired faculty have experienced expediency in their first two years at work. These individuals were used to have multiple tasks in their previous employment. They did not only teach but also implemented different regional and national programs including those from the Division office. Similarly, the newly-hired faculty participated and were involved in different areas of responsibilities and activities such as the accreditation (AACCUP) and ISO certification. As divulged to the researchers:

Participating in AACCUP and ISO is actually the same as DepEd. It was like we were participating in School-based Management (SBM) evaluation when we worked out for accreditation for another level(P2).

Somehow, this work was not new. As a result, they found these activities non-stressful for they had been exposed to it. They were confident they have done what was expected of them. It was highlighted by one of them,

If it is 18 units, it is really 18 units and when you are given teaching load beyond that, we would receive something for the overload (P3).

If the faculty's workload is beyond 18 units, they would receive additional payment. On the contrary, DepEd teachers who had handled more than 18 units including the advisory classes, had never enjoyed the same privilege. Others shared on subjects they handled which were not taught on a daily basis. These were scheduled on Monday-Wednesday, Monday-Wednesday-Friday or Tuesday-Thursday system. Some of them had four sections/classes to teach with two lesson preparations only (P6, P7). For these, they found it advantageous to be employed at BukSU, for there are a manageable workload and reasonable pay for extra teaching loads.

In their previous schools, learners could not usually submit requirements and outputs on time. The usual reason for that was the lack of money. Because of this, the teachers would usually extend the deadline for humanitarian reasons. However, in their present employment, they noted that learners comply with the requirements because they have the resources.

Some newly-hired teachers considered their first two years at BukSU as stress-free and convenient with a manageable workload. As a result, they have quality time for themselves and for their loved ones. Thus, they have work and life balance. Accordingly, they can provide quality teaching for they have enough time except for those who are still in the adjustment period. All these experiences constituted the so-called joys of teaching.

Contrary to their joys of teaching, the newly-hired teachers had also struggling experiences particularly in dealing with parents and learners; and on the content of the subjects they are teaching, appropriate pedagogy, and teacher evaluation. Many times, parents complained over the low grades of their children and on the new grading system when the $\mathrm{K}$ to 12 programs were newly implemented. Some complaints have reached to the principal before it was settled at their level. Parents in laboratory schools would always monitor their children (P1, P2, P3, P4). Because of this, teachers tried their best in the delivery of their lessons.

For the teachers to resolve the problems concerning children, they called the attention of parents. But there were cases when parents visited the school to confront teachers personally. Parents' complaints must be resolved and addressed at the level of the teacher only if parents would not go directly to the principal. Accordingly, teachers do not have control over this case. One faculty shared when she called parents and had a conference with them:

I talked with the parents and the students. And I explained it to them and fortunately, they were able to understand (P4). For responsible and responsive parents, it was easy to deal with them. As one of them recalled,

It was easier to reach out to those kinds of parents (P3).

Some of the newly-hired faculty invested so much time on discerning what teaching strategies and approaches appropriate to their learners. As one of them unveiled, It was difficult and I even googled strategies in teaching for tertiary education (P5).

Another participant added:

On the strategy of teaching, it was difficult and I need to ensure it would be enjoyable and interactive (P1).

They meant it when they said that they need to be innovative and creative to provide quality teaching and achieve effective learning. Thus, it took them more time to prepare for their lessons and select the appropriate pedagogy. Special efforts should be exerted by these teachers to provide effective teaching in the classroom (Faciolan \& Guhao, 2016). Some have searched for more readings using the internet for them to provide updated content, effective, and appropriate teaching methods for productive learning. This means they do not rely on the textbooks provided to every learner. One of them highlighted:

I cannot afford to go to my class unprepared (P1). 
Even the experienced teachers, when they transfer to a new job at a new college or university, they feel tested (Menges, 1996). For this faculty, it is a challenge for two reasons. She would be humiliated if she was not ready to teach the kids, and this would be reflected in the learners' output. The faculty invested so much time in selecting appropriate strategies and for preparing the instructional materials. She made sure that teaching and learning processes were enjoyable and interactive. Otherwise, learners would find the process boring and mind-numbing. Second, parents were monitoring the children's output. The parents would likely complain if they knew the teacher was not doing well for her class.

Teachers are expected with professional knowledge for them to establish an environment for effective and valuable learning outcomes (Schleicher, 2018). Therefore, lesson preparation should be done carefully and ensure effective learning. For the teachers to sustain in their teaching profession, they need to overcome all the difficulties in lesson preparation (Faciolan \& Guhao, 2016). They need to surpass their struggles in delivering the lessons. One way they can do it is by being mentored by senior and seasoned faculty. However, none of them has shared as to how they experienced mentoring with colleagues. One participant disclosed:

Parents could not understand the new grading system. So, that is why if their children have very low grades, they are angry (P4).

Thus, teachers feel pressured. On test construction, a participant considered the quality of the assessment, especially grammar, as very important. She mentioned,

It is here in the lab school that I truly feel tired. It is no joke to be a teacher(P1).

In realizing her identity, roles, and meeting parents' expectations, it was also at the expense of her well-being. She felt tired. Villarosa and Ganotice (2018) cited that psychological well-being is influenced by work-related stress. This experience could be detrimental to teacher's comfort, convenience and peace of mind in the workplace. Teachers need to work with parents and colleagues and respond to learners' differences to provide the holistic development of the learners (Schleicher, 2018). One of them expressed, My experience in instruction is painful at first (P5).

And this is due to culture shock. The new faculty could immediately experience the momentous shift happening around (Yeo, Bennett, McNichol, \& Merkley, 2015). The expectation is different from reality. As a faculty, she set high standards for learners but they could not make up with the standards. In the end, they received low marks. At the end of the semester, this faculty got a low rating from the students in the evaluation of teaching performance. She could not believe it since she followed the syllabus religiously. All the activities in the syllabus were implemented with students. When graduating students were bombarded with requirements, they rated her also with very low performance. She added:

It was so far my first student evaluation. I got the lowest score among the newly-hired faculty in the College of Education. When I read the evaluation results, I cried (P5).

Sadness was seen in her eyes when she shared this, though she was smiling at her painful experience with students. She added that she had kept the evaluation forms. As mentioned by Bartell (2004), the failure to provide for careful support and thoughtful development of teaching expertise over time may be the reason for the early years of teaching to be often characterized by a "sink-or-swim" or "survival" mentality.

Some of the newly-hired teachers had struggled as they performed their job. These struggles may potentially lead them to stress, anxiety, despair and frustrations. That is why it is a serious concern for administrators to monitor if these conditions are experienced by these teachers. Ikemoto, Taliaferro, and Adams (2012) indicated that administrative support plays a major role in teacher retention.

Teachers are expected with professional knowledge for them to establish an environment for effective and valuable learning outcomes (Schleicher, 2018). Therefore, lesson preparations should be done carefully and ensure effective learning. They need to surpass their struggles in delivering the lessons (Faciolan \& Guhao, 2016).

\section{Successes and Pains of Learning}

The newly-hired faculty shared their experiences after their two years of teaching at the university. Their sharing was on professional development experiences here at the university. These experiences are grouped into two: successes and pains. For their successful experiences, meaning units include the privileges, compensation, addressing personal problems for professional growth, and dealing with colleagues. Painful experiences refer to their difficulties in graduate studies.

Professional growth and development of newly-hired faculty are necessary for them to be proficient in performing their tasks. These may improve their social and economic status when they are sent to different seminars and schooling for free with free transportation. In training, they could get along with others. From the seminar-workshops attended, they can accumulate certificates received which are 
useful for their future promotion. Plainly, these are some of the privileges they availed at BukSU.

Some newly-hired faculty were able to join different professional development activities. Later on, a few of them got additional compensation when their ranks were upgraded when they came to BukSU. Other benefits that some of them enjoyed, include the free tuition and transportation for those who are pursuing their doctoral studies. Being sent to seminars with free transportation with allotted allowances is a privilege. As shared:

Even if I am new here, I enjoyed the same privilege, the scholarship" (P3).

These newly-hired faculty tried their best to pursue their studies and attended seminar-workshops for their professional growth. Working conditions and administrative support at schools could influence teachers' decisions to depart or to remain (Allensworth, Ponisciak, \& Mazzeo, 2009). These faculty were delighted with the benefits they have obtained from the university. These may have motivated them to function well on their assigned tasks and responsibilities. In fact, they found satisfaction as their efforts exerted were paid off with additional compensation. As divulged:

Without waiting for many years to be promoted, here there is no idea of labor of love here. You are well-paid (P6).

Promotion for newly-hired faculty could be possible since they are given the chance to upgrade their positions or ranks. Bartell (1995) cited the systematically planned program of induction that aims to support new teachers not just to live to tell the tale, but to succeed and prosper.

These newly-hired faculty had also some challenges and problems. However, they learned to cope with all of these, and these became some of their successes. They learned to adjust to nerve-wracking instances while these have made them maintained their emotional well-being. As unveiled: I have turned my frustration and pain into positivity (P5). Eventually, these made them even stronger in facing different challenges in life (P4, P6, P7). As one faculty highlighted, They're my strength... a stepping stone in addressing future challenges (P4).

It would be a big help for teachers to acknowledge and address their challenges to prepare for their future work, fostering well-informed and confident teacherleaders (Barker, 2012). Furthermore, they have shown the willingness to improve professionally by facing each challenge and by overcoming it. They have shown a positive outlook in life. Gradually, they gained so much self-confidence. Having a harmonious relationship was aimed at by most participants. With the flexibility of the newly-hired faculty, they could easily mingle and affirm their colleagues. This led them to a stress-free working environment. A good relationship was a great factor for a stress-free environment. Some of them could easily adjust to their associates as they went along with them effortlessly. This means they have blended well with colleagues (P3, P6). As shared:

I cannot do it or make it without the help of colleagues (P4). When teachers are provided with support that promotes the understanding of the strategies that assist them in becoming proficient educators, their decision to remain in the field is more likely (Albert, 2017). This proves that the importance of having their colleagues as they work with them is acknowledged. Rice (2010) cited that teachers retain their work because of their supportive relationships with colleagues. There may be conflict sometimes in dealing with colleagues. This was affirmed by one faculty who said:

There were little conflicts but not to the extent that it cannot be settled (P3). Although this is not about conflict, one of them said, I have a problem with trust, I just can't open up with somebody or anybody (P5).

This faculty expressed that she needs to filter what she should share with anyone because she was afraid that the person would judge her. She considered herself to have an anti-social behavior. Thus, she needed to select people whom she could deal with and trust. Some of them saw their colleagues as competitive which sometimes caused their low self-confidence and doubt with their performance in the new workplace. Although some newly-hired faculty encountered difficulties in professional development, they still had the desire to pursue their studies. Conversely, one faculty stated,

I stopped after a year, after getting or completing the academic requirements (CAR). I got lazy to go back to school. I think it's a problem" (P2).

This teacher got tired of pursuing her Doctorate studies. Some of them had difficulties in complying with the requirements, while some had difficulties in maintaining a balance in allotting time for work, studies and family. Aside from time, some of them reasoned out as not having enough finances. This implies that some of them are not yet informed with financial support the university has been extending to the faculty.

\section{Challenges and Privileges of Serving}

Newly-hired teachers have also experienced in working on the university's thrusts along with research, extension and IM development. These experiences are classified as privileges and challenges they encountered. Privileges in serving include the chances of conducting research and disseminating results; the importance, interest, and attitudes to- 
ward research; plans and importance of IM's production; interest and benefits in extension; and, additional benefits. The challenges are the inappropriate IMs to learners; negative perception toward extension; lack of training on IMs production; and, non-productivity.

This theme uncovered the journey of the newly-hired faculty in research, IM production and extension. Most of the participants are on progress or still need to be acquainted with the necessary information for them to become efficient in these areas. Higher education faculty are expected to acquire knowledge of research and publication (Wa-Mbaleka, 2015). The faculty needed to embrace the culture of higher education in conducting research, creating instructional materials, and participating in extension activities.

Surprisingly, they revealed their desire and interest to engage in research (P1, P4, P5 P6, P7) but few have expressed the need for further training. There is a need for a wide dissemination of the call for in-house review. As one participant revealed: I love to do research. The problem was I don't have the background and proper training yet (P5). Another participant shared: I like to conduct research but usually I am not informed about it (P1).

These newly-hired faculty would love to engage in research but then they could not manage their time for they needed to engage in other areas, too most especially in instruction. As expressed: So when I will do my own research here in BSU, I don't know how to budget my time anymore (P4).

As a result, they could not conduct research at all. Others are on the process of doing research as they have just presented in the in-house review. On the contrary, some participants were already enjoying the opportunities to conduct research and had presented them to international and local conferences (P2, P8). Workshops and conferences are some of the professional activities (Bilbao, Corpuz, Llagas, \& Salandanan, 2018). They need to be exposed to different seminar-workshops to be equipped with the necessary information and could participate actively in research.

Instructional Material Production is one of the areas in which the newly-hired faculty experienced difficulty. They were interested also in IMs production (P1, P4, P5, P7). However, some faculty would consider IM production as not suitable to their learners because they were teaching in basic education (P2, P3). Accordingly, they were told to create IMs for higher education. And this is in conflict with their interest because instructional materials were not intended for their learners. Furthermore, they were also addressing the concerns of parents of paying the books and could not be used by the learners if these were replaced with IMs developed by them. Surely, parents would have a tirade over this. As a participant mentioned,

I wish there would be a model on how to develop an IM. It's like I lack knowledge and information about it (P1). She believed that she could make an IM as long as she would be provided with enough information, knowledge, and samples on how it is done. One of them added, That's the problem. I really don't have an idea on how to make an IM (P5). They believe that if they were given the chance to learn more about IM production, they could surely create and utilize the instructional materials for their teaching (P1, P4, P5). This belief revealed their interest and their self-efficacy toward IMs production.

Extension activities could help the community in terms of development. That is why, the participation of the faculty could not only have benefitted teachers with incentives but also contributed to the development of the community they are serving. One faculty expressed her self- actualization for being actively involved in extension:

Extension activities are full of fun. It was very fulfilling because you could see and meet the beneficiaries and I am happy with it (P5).

Some faculty have enjoyed participating in the extension activity as they could foster their love and service to the community they were helping (P3, P4, P5). On the other hand, someone mentioned:

I do extension activities. Supposedly during weekends, you have to rest but since we have a lot of things to do we have no choice but to work (P6).

Accordingly, their department was active with extension activity as they were all encouraged to participate. However, one of them expressed otherwise, The extension is hard (P7).

It is pretty obvious that the newly-hired faculty have mixed perceptions and attitudes toward the extension responsibilities. The newly hired faculty benefitted from additional incentives in conducting extension services such as Collective Negotiation Agreement (CNA), service credits and other assistance for their active participation in various programs' extension activities. As highlighted, ...we have CNA here (P4).

The factors that affect teachers' entry and retention are salaries, preparation, mentoring and support, and working conditions (Darling-Hammond, Wei, et al., 2012). These additional benefits are not available in their previous employment because it was exclusively given to State Universities and Colleges, like the Bukidnon State University employees. Regardless of the difficulty experienced by the newly-hired faculty in research, production and extension, they are still eager to accomplish something in all areas and benefit from 
these as they were compensated according to their work or service rendered. If they felt challenged and satisfied in their work, they are inclined to stay and pursue a long-term involvement (Bartell, 2004).

Based on the results, the study presents the generated conceptual framework of paradoxical lived experiences of newly-hired faculty in a university setting. Figure 1 illustrates the composition of the framework. The innermost core is the newly-hired faculty of the Bukidnon State University. They are placed at the center for this study revolved around the lived experiences of these individuals. The next inner circle has the emergent themes: joys and struggles of teaching; successes and pains of learning; and privileges and challenges of serving. Outside the circular figure are the pillars of higher education institutions such as instruction, professional development, and research, production and extension. This was the scope of the inquiry.

The joys and struggles of teaching are associated with the instruction. These include adjustments of the newly-hired faculty in instruction; pedagogy; dealing with parents and learners; and, manageable workload. On the other hand, successes and pains of learning are related to dealing with colleagues; coping mechanisms; and professional growthrelated activities by which the newly-hired faculty benefitted. Moreover, in privileges and challenges of serving are connected with the participation of these faculty in research, production, and extension. Hence, this framework represents the positive and negative experiences.

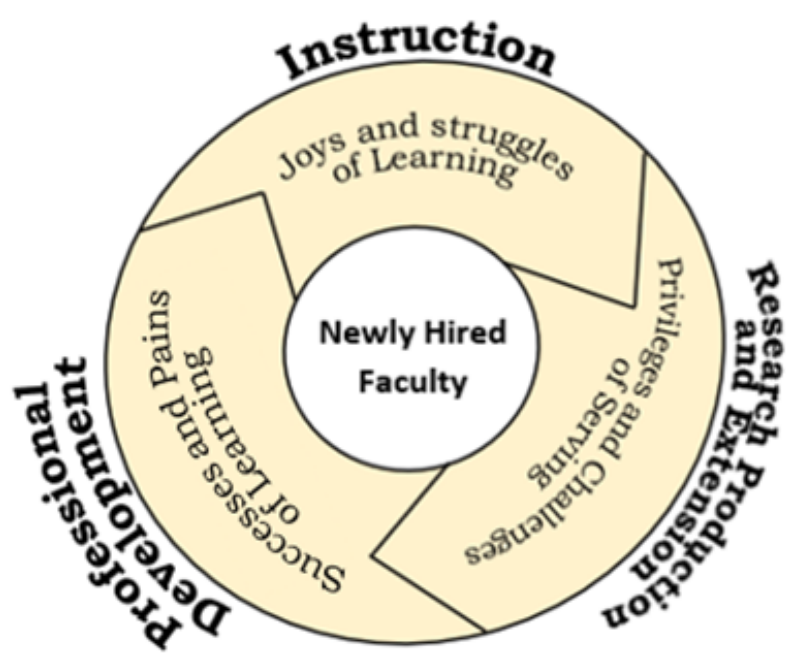

FIGURE 1. Conceptual framework of paradoxical lived experiences

\section{CONCLUSION}

It was generalized that the newly-hired faculty had varied experiences in their first two years at the Bukidnon State University. These experiences are paradoxically classified as the joys and struggles of teaching; successes and pains of learning; and the privileges and challenges of serving. These three paradoxes have constituted the most emergent themes of their lived experiences.

Generally, these teachers have experienced ups and downs in their first two years, but it is safe to claim that they have a better work environment which is characterized as stressfree, less-hassled, expedient, with a manageable workload, favorable schedules, work-life balance, more privileges, unique compensation, and better work relations with colleagues.

On the other hand, they have experienced struggles of teaching in dealing with learners and parents, in preparing their lessons especially in the selection of strategies, and in constructing tests in English. They also experienced the pains of learning with competitive colleagues and in finishing graduate studies. They had also challenges of serving mostly for being unproductive in research and instructional materials development.

Most of the lived experiences of newly-hired teachers are centered on instruction. This was because they need to be acquainted with other areas. Since they underwent or are still undergoing the adjustment period, it would be challenging on their part to be active and productive simultaneously in four core functions of the university. Thus, they need to be trained continuously with administrative support and mentoring of colleagues. With support from the administration and their colleagues, these faculty would certainly grow and develop professionally. Moreover, they would progress in areas they have limited experiences in, and consequently, increase their productivity. 


\section{LIMITATIONS AND RECOMMENDATIONS}

This study took place in Bukidnon State University, thus, the applications of these findings are limited. To enhance the generalizability of these findings, otehr similar studies must be conducted with different sample.

This study has come up with these recommendations: (1) Administrators need to conduct training, or seminarworkshops on how to deal with confrontational parents, and/or people with difficult personalities so that these teachers may be able to manage and address parents' complaints; (2) Administrators shall provide training to newlyhired teachers on different pedagogies and teaching strategies for diverse learners; (3) Senior faculty shall perform the role as mentors to newly-hired teachers so that the latter can fully adjust and integrate themselves to their new work environment and on different roles and responsibili- ties that each of them shall fulfill and accomplish; (4) Since newly-hired teachers have expressed interest in research, the Research Coordinator and Research Director may provide more continuing professional development opportunities in which these teachers may improve and eventually engage in research and publication; (5) Instructional Materials Development Center shall provide more training that can improve newly-hired teachers' skills and competence necessary in developing instructional materials; and (6) IMDC shall formulate clear policies whether newly-hired teachers who are teaching at the basic education departments shall be required or not in developing instructional materials and or policies that promote teachers' developed instructional materials intended for learners instead of purchasing books from different publishing companies.

\section{REFERENCES}

Albert, E. (2017). Overcoming the challenges of retaining novice teachers in a county public school (Unpublished master's thesis). Walden University, Minneapolis, Minnesota.

Allensworth, E., Ponisciak, S., \& Mazzeo, C. (2009). The schools teachers leave: Teacher mobility in Chicago public schools. In Consortium on Chicago School Research, Chicago, IL.

Barker, C. (2012). Cultural studies. New York, NY: Sage Publications.

Bartell, C. A. (1995). Shaping teacher induction policy in California. Teacher Education Quarterly, 5, 27-43.

Bartell, C. A. (2004). The challenges facing beginning teachers. In Cultivating high-quality teaching through induction and mentoring. London, UK: Oxford Press.

Bilbao, P. P., Corpuz, B. B., Llagas, A. T., \& Salandanan, G. G. (2018). The teaching profession. Quezon City, Philippines: Lorimar Publishing.

Creswell, J. W., \& Creswell, J. D. (2017). Research design: Qualitative, quantitative, and mixed methods approaches. New York, NY: Sage Publications.

Darling-Hammond, L., Wei, R. C., et al. (2012). Teacher preparation and teacher learning: A changing policy landscape. In Handbook of education policy research. London, UK: Routledge.

Dias-Lacy, S. L., \& Guirguis, R. V. (2017). Challenges for new teachers and ways of coping with them. Journal of Education and Learning, 6(3), 265-272. doi:https://doi.org/10.5539/jel.v6n3p265

Didatoon, N. (2016). Instructional difficulties of newly hired teachers (Unpublished master's thesis). Bukidnon State University, Malaybalay City, Philippines.

Faciolan, M. C., \& Guhao, E. S. (2016). Pedagogical journey of newly hired teachers: Stories to tell. International Journal of Scientific \& Engineering Research, 7(9), 1674-1693.

Gam, R. P. (2018). Teachers' experiences in handling students with learning difficulty. International Journal of Humanities, Arts and Social Sciences, 4(4), 179-185. doi:https://doi.org/10.20469/ijhss.4.10003-4

Ikemoto, G., Taliaferro, L., \& Adams, E. (2012). Playmakers: How great principals build and lead great teams of teachers. New Leaders, 4(6), 45-60.

Joonlaoun, P. (2017). Remitting behaviors and intention to return home of Thai migrant workers in australia: A study of income, employment and legal satisfaction. Journal of Advances in Humanities and Social Sciences, 3(1), 29-41. doi:https://doi.org/10.20474/jahss-3.1.3

Lancu, L. (2013). 5 common challenges facing educators at school beginning and tools to address them. Retrieved from https://bit.1y/3dDrOFD

Menges, R. J. (1996). Experiences of newly hired faculty. To Improve the Academy, 15(1), 169-182. doi:https://doi.org/ 10.1002/j.2334-4822.1996.tb00308.x 
Morrow, R., Rodriguez, A., \& King, N. (2015). Colaizzi's descriptive phenomenological method. The Psychologist, 28(8), 643-644. doi:https://doi.org/10.5172/conu.2011.163

Peria, A. (2015). Classroom experiences of newly hired teachers. a phenomenological study (Unpublished master's thesis). Bukidnon State University, Malaybalay City, Philippines.

Pwint, O. M. N. C. H. (2016). The status and the problem of western vocal music teaching in Myanmar. Journal of Advanced Research in Social Sciences and Humanities, 1(1), 9-17. doi:https://doi.org/10.26500/jarssh-01-2016-0102

Rice, J. K. (2010). The impact of teacher experience: Examining the evidence and policy implications: Brief no. 11 (Technical report). National Center for Analysis of Longitudinal Data in Education Research, Durham, NC.

Schleicher, A. (2018). Valuing our teachers and raising their status: How communities can help, international summit on the teaching profession. Paris, France: OECD Publishing.

Villarosa, J. B., \& Ganotice, F. (2018). Construct validation of Ryff's psychological well-being scale: Evidence from filipino teachers in the Philippines. Philippine Journal of Psychology, 51(1), 1-20. doi:https://doi.org/10.31710/pjp/0051.01 .01

Wa-Mbaleka, S. (2015). Factors leading to limited faculty publications in Philippine higher education institutions. International Forum, 18(2), 121-141.

Yeo, M., Bennett, D., McNichol, J. S., \& Merkley, C. (2015). New faculty experience in times of institutional change. Canadian Journal of Higher Education, 45(4), 283-297. 